\title{
Governança Corporativa e Internacionalização: uma ANÁLISE DOS EFEITOS NAS EMPRESAS BRASILEIRAS
}

\author{
Corporate Governance and Internationalization: a review of \\ effects on Brazilian companies
}

\section{Luzélia Calegari Santos Moizinho}

Aluna Bolsista do Programa de Pós-graduação em Administração. Universidade Federal de Uberlândia. Uberlândia, MG. Brasil. E-mail: luzeliacalegari@hotmail.com

\section{Rogério Borges Borsato}

Aluno do Programa de Pós-graduação em Administração. Universidade Federal de Uberlândia. Uberlândia, MG. Brasil. E-mail: rogerioborsato@uol.com.br

Fernanda Maciel Peixoto

Professora Adjunta de Finanças. Universidade Federal de Uberlândia. Uberlândia, MG. Brasil. E-mail: fmacielpeixoto@gmail.com

\section{Vinícius Silva Pereira}

Professor Adjunto de Finanças. Universidade Federal de Uberlândia. Uberlândia, MG. Brasil. E-mail: vinicius@fagen.ufu.br

\section{Resumo}

Este trabalho tem por objetivo analisar os efeitos da internacionalização sobre a qualidade da governança corporativa, bem como o efeito da governança corporativa na internacionalização. Como objeto de estudo considerou-se as empresas brasileiras não financeiras de capital aberto, no período de 2005 a 2010, e para o tratamento dos dados utilizou-se do modelo de regressão com dados em painel. Como variáveis de internacionalização das empresas, utilizouse a exportação sobre a receita total e a comercialização de ADRs. Já para a governança corporativa, criouse um índice pelo método da Análise Fatorial. Os resultados evidenciaram que as exportações tiveram relação positiva com a qualidade da governança, enquanto a comercialização de ADRs apresentou relação negativa. Como contribuição os resultados apontaram que empresas com níveis de governança mais elevados apresentam possibilidades de incrementar suas receitas pelas exportações, em contrapartida, empresas com baixos índices de governança tendem a buscar financiamentos no exterior como forma de mitigar os problemas de gestão. Sugerem-se como futuras pesquisas a inclusão de outros indicadores de internacionalização.

Palavras-chave: Internacionalização. Governança Corporativa. Exportação. ADRs. Empresas Brasileiras.

\section{Abstract}

This work aims to analyze the effects on the internationalization quality of corporate governance, as well as the effect of corporate governance on internationalization. As an object of study we have considered the Brazilian non - financial listed companies in the period 2005-2010, and for the treatment of the data it was used the regression model with panel data. As variables of internationalization of companies it was used the exportation level on sales and trading of ADRs. For corporate governance, we created an index using the Factor Analysis method. The results showed that exports had a positive relationship with the quality of governance, while the trading of ADRs showed a negative relationship. As contribution these results indicates that firms with higher levels of governance have opportunities to increase their sales from exports, on the other hand, companies with low levels of governance tend to seek financing abroad as a way to mitigate the problems of managing. It is suggested as future research to include other indicators of internationalization as a percentage of foreign assets and percentage of foreign employees.

Keywords: Internationalization. Corporate Governance. Exports. ADRs. Brazilian Companies. 


\section{INTRODUÇÃo}

A partir da década de 1990, com a abertura da economia brasileira, intensificou-se o processo de globalização da economia nacional e houve um consequente aumento das exportações das empresas brasileiras. A série histórica da balança comercial revela que o crescimento das exportações anuais foi de $330 \%$ nos últimos dez anos. Em 2003, o volume de exportações totalizou 73,2 bilhões de dólares. Em 2011, o Brasil apresentou o seu volume recorde de exportação atingindo 256,04 bilhões de dólares e em 2012 manteve os mesmos patamares totalizando 242,6 bilhões de dólares. (UNCTAD, 2013)

As exportações consistem em uma das formas de entrada das empresas no mercado internacional. Empresas procuram promover o crescimento de seus resultados, diluir o risco de suas operações locais e obter vantagem competitiva em relação aos seus concorrentes. (JOHANSSON, 1994)

No processo de internacionalização das empresas, destaca-se o papel da governança corporativa. As empresas que adotam mecanismos para melhorar o seu gerenciamento, conforme os princípios da governança corporativa, tendem a agregar mais valor às suas ações. Esses mecanismos objetivam reduzir a assimetria de informações entre os agentes, proteger os acionistas minoritários e manter conselhos mais eficientes e produtivos. (RAPPAPORT, 1998; ANDRADE; ROSSETTI, 2004)

Dessa forma, a aderência aos padrões de governança corporativa recomendada pelos agentes de mercado possibilita uma melhor avaliação de suas ações (SILVEIRA, 2005) e, consequentemente, oportunidades de captação de recursos a custos mais baixos (ROGERS, 2006). Sabe-se que uma das formas de se captar recursos no mercado de capitais é por meio de emissão dos American Depositary Receipts (ADRs). Estudos evidenciam que empresas que emitem ADRs tendem a possuir um maior nível de governança, consequentemente um menor risco e captações de recursos próprios a custos menores. (IQUIAPAZA; LAMOUNIER; AMARAL, 2008; LAMEIRA, 2012)

Por outro lado, estudos recentes questionam uma possível relação contrária, como a pesquisa de Andrade e Galina (2013) comprovando que o grau de internacionalização tem efeito inverso no desempenho das firmas e ocorre em países com fraca governança corporativa e baixa competitividade empresarial.

Quanto à forma de captação de recursos, também há outros entendimentos de internacionalização de empresas. Pereira e Sheng (2013), por exemplo, utilizam o indicador Degree of Internationalization (DOI) da UNCTAD (2013), que leva em consideração as vendas, ativos e pessoas no exterior. Os autores alertam para o fato de que algumas empresas optam pelo financiamento local, via endividamentos com bancos, mesmo a custos mais altos, para não alterarem o nível de concentração da propriedade. Por sua vez, a concentração de propriedade é uma das variáveis estudadas dentro da temática de governança corporativa, como ressaltam os estudos de Morck, Shleifer, Vishny (1988), Claessens et al. (2002), Pereira e Sheng (2013). Assim, apesar de algumas evidências empíricas terem tangenciado possíveis efeitos entre internacionalização $e$ as variáveis de governança corporativa, pouco se conhece da relação entre estas duas variáveis.

Nesse contexto, este estudo se propõe a analisar os efeitos da internacionalização sobre a qualidade da governança corporativa, bem como o efeito da governança corporativa na internacionalização. Como objeto de estudo será considerado as empresas brasileiras não financeiras de capital aberto, no período de 2005 a 2010 e o tratamento dos dados será feito por meio da modelagem de dados em painel.

O estudo se justifica pela relevância dos dois temas apresentados - internacionalização e governança corporativa - no atual cenário, pela busca do melhor entendimento entre a relação dos dois temas e pelo reconhecimento de que empresas com melhores práticas de governança possuem mais oportunidades em realizar investimentos externos (PEREIRA, 2013). Do ponto de vista do ineditismo, este trabalho analisa governança corporativa e o processo de internacionalização, tema ainda pouco explorado na literatura. A escolha pelas empresas de capital aberto na BM\&FBOVESPA se deve a disponibilidade dos dados.

Além desta introdução, o artigo está estruturado com uma revisão teórica das literaturas de governança corporativa e internacionalização na segunda seção. A terceira seção apresenta a metodologia de pesquisa do estudo. A quarta seção descreve os resultados obtidos. A quinta seção apresenta as considerações finais da pesquisa. 


\section{Referencial Teórico}

Esta seção expõe uma revisão da literatura nacional e internacional acerca dos conceitos de internacionalização e dos mecanismos de governança corporativa, bem como aspectos basilares da temática da relação entre internacionalização e qualidade da governança coorporativa.

\subsection{Internacionalização}

Segundo Ohmae (1995), diversas transformações ocorridas na economia têm levado à unificação dos mercados mundiais de bens, mão de obra, serviços e capital. Eventos como a o surgimento da Internet tornaram o cenário competitivo mundial com menos obstáculos, reduzindo o poder dos Estados e aumentando a globalização. (FRIEDMAN, 2005)

Nesse contexto de globalização, as empresas têm investido na internacionalização das suas atividades buscando a obtenção de benefícios. Segundo Barreto e Rocha (2003), a internacionalização é o processo de envolvimento das empresas com o exterior em qualquer um dos dois sentidos, para dentro, por meio de importação, licenças de fabricação, contratos de franquia ou tecnologia, ou para fora, por meio de exportações, concessão de licenças de fabricação, franquias, tecnologia ou investimento direto no exterior. E para cada tipo de atividade, há um grau de risco e investimento diferenciado, conforme Figura 1.

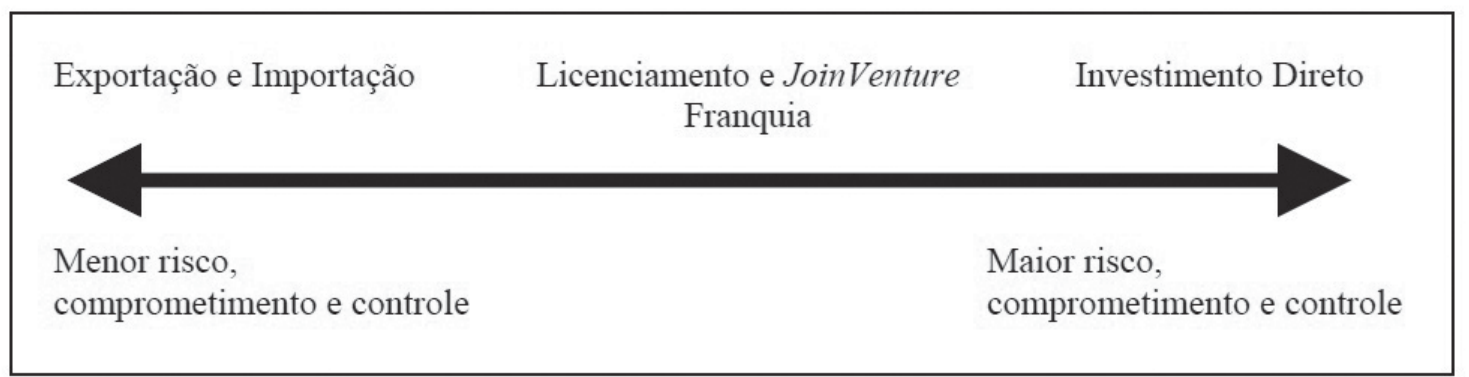

Figura 1: Níveis de internacionalização

Fonte: Adaptada de Nickels e Wood (1999)

Em seus estudos, Dunning (1996) identificou quatro motivações econômicas básicas para as empresas se internacionalizarem: a busca por novos mercados; a busca por novas fontes de recursos; a ênfase na eficiência dos mercados globais; e a busca de ativos estratégicos. Porém, também existem riscos e custos que envolvem a internacionalização das empresas, como: custos crescentes de coordenação e de governança, os riscos relacionados às desvantagens de uma empresa ser estrangeira e de ser nova nos mercados, além dos riscos políticos e econômicos aos quais as empresas que se internacionalizam estão sujeitas.

Além desses fatores, Barcelos (2010) consolida outros benefícios e custos da internacionalização das empresas, apontados por diversos autores, conforme demonstrado no Quadro 1.
O trabalho de Oesterle, Richta e Fisch (2013), a partir da análise de dados em painel das 102 maiores companhias alemães no período de 1990 a 2006, conclui que não existe uma relação linear entre a concentração de propriedade de capital e internacionalização da empresa. Os autores argumentam que acionistas de organizações muito dispersas não têm condições e tampouco interesse em monitorar como os gestores estão administrando seus recursos, dessa forma, os gestores tem relativo grau de liberdade para usufruir de benefícios privados de controle. Neste caso, a internacionalização não é desejável para os acionistas minoritários. Por outro lado, para os acionistas controladores, a internacionalização apresenta melhores oportunidades de maximizar sua riqueza, sem perder o controle da gestão. 


\begin{tabular}{|c|c|}
\hline Benefícios & Custos \\
\hline $\begin{array}{l}\text { Diluição de custos centrais, como } \\
\text { os administrativos e os de Pesquisa } \\
\text { e Desenvolvimento (P\&D), para } \\
\text { diversos países. }\end{array}$ & $\begin{array}{l}\text { O custo de ser estrangeiro, que } \\
\text { inclui o desconhecimento e a } \\
\text { dificuldade de tratar com } \\
\text { contextos de mercado e culturais } \\
\text { muito diferentes daqueles do } \\
\text { país de origem. }\end{array}$ \\
\hline $\begin{array}{l}\text { Maior capacidade de resposta aos } \\
\text { clientes internacionais, resultante } \\
\text { da maior proximidade física, que } \\
\text { favorece a eficiência logística, e } \\
\text { da melhor compreensão dos } \\
\text { mercados externos e das culturas } \\
\text { locais, que favorece o } \\
\text { entendimento das necessidades } \\
\text { dos clientes estrangeiros. }\end{array}$ & $\begin{array}{l}\text { O aumento dos custos gerais de } \\
\text { coordenação e governança, pois } \\
\text { a complexidade e diversidade } \\
\text { das operações internacionais } \\
\text { impõem uma sobrecarga aos } \\
\text { recursos existentes e exige novos } \\
\text { recursos especializados. }\end{array}$ \\
\hline $\begin{array}{l}\text { Maior aprendizagem e experiência } \\
\text { internacional. }\end{array}$ & $\begin{array}{l}\text { O custo de ser novo no mercado, } \\
\text { que engloba custos com a } \\
\text { instalação de fábricas, } \\
\text { estabelecimento de sistemas } \\
\text { gerenciais internos e de uma } \\
\text { rede externa de negócios. }\end{array}$ \\
\hline $\begin{array}{l}\text { Acesso a recursos mais baratos ou } \\
\text { escassos em países externos, como } \\
\text { mão-de-obra, tecnologia, ou } \\
\text { competências específicas de um } \\
\text { determinado país. }\end{array}$ & \\
\hline $\begin{array}{l}\text { Maior capacidade de } \\
\text { monitoramento global dos } \\
\text { concorrentes, mercados e outras } \\
\text { oportunidades de lucro. }\end{array}$ & \\
\hline $\begin{array}{l}\text { Melhor capacidade de subsidiação } \\
\text { cruzada, discriminação de preços } \\
\text { e potencial de arbitragem com o } \\
\text { aumento do escopo geográfico de } \\
\text { atuação. }\end{array}$ & \\
\hline $\begin{array}{l}\text { Benefícios de marketing por meio } \\
\text { do efeito-demonstração que a } \\
\text { empresa consegue nos seus } \\
\text { mercados de origem. }\end{array}$ & \\
\hline
\end{tabular}

Quadro 1; Benefícios e Custos da internacionalização das empresas

Fonte: Adaptado de Barcelos (2010)

Na análise de 1.776 empresas latino-americanas, Pereira e Sheng (2013) concluíram, entre outros aspectos, que existe uma relação inversa entre o nível de internacionalização das empresas e o nível de concentração de propriedade e que há uma simultaneidade na determinação entre o nível de internacionalização e concentração de propriedade. Como contribuição principal, os autores sugerem que os gestores privilegiam a internacionalização como forma de maior prospecção e obtenção de recursos necessários ao crescimento da firma mesmo que para isso incida maior controle e monitoramento de suas decisões.

Nesse cenário, ficam reconhecidas a importância da internacionalização e a compreensão do seu relacionamento com as práticas de governança corporativa.

\subsubsection{Governança Corporativa no Contexto da Internacionalização}

O conceito de governança corporativa é definido por Shleifer e Vishny (1997) como o conjunto de mecanismos para assegurar às pessoas o retorno de seus investimentos. Os autores partem do pressuposto do conflito de agência e abordam a importância da proteção legal e concentração de propriedade no mercado global. Concluem que países com sistemas legais com forte proteção dos acionistas e estrutura de propriedade dispersa apresentam melhores práticas de governança corporativa. Por outro lado, países com fraca proteção legal e concentração de propriedade centralizada tendem a apresentar falhas na compensação dos executivos, contratos incompletos e manipulação de informações.

La Porta et al. (2000) advogam a importância do sistema legal e da aplicação das leis (enforcement) como um elemento eficiente de proteção aos investidores da expropriação de gestores oportunistas. Dessa forma, países que apresentam obstáculos à expropriação de minoritários e dificultam o uso de benefícios privados de controle tendem a obter financiamentos externos em melhores condições.

A necessidade de captação de recursos financeiros em mercados internacionais corroborou com o desenvolvimento de mecanismos de governança corporativa no Brasil e no mundo. Nesse cenário, empresas com melhores práticas de governança corporativa tendem a agregar mais valor às suas ações, na medida em que fornecem aos seus investidores, mecanismos que lhes assegurem proteção superior. (RAPPAPORT, 1998; ANDRADE; ROSSETTI, 2004; NAKAYASU; 2006)

Correia, Amaral e Louvet (2011) argumentam que esses mecanismos de governança corporativa, sob a ótica do controle dos problemas de agência envolvem: (1) composição do conselho de administração; (2) estrutura de propriedade e controle; (3) modalidades de incentivo aos administradores; (4) proteção aos 
acionistas minoritários; e (5) transparência das informações publicadas.

Nesta direção, a OCDE lista como prioridades no processo de reforma da governança corporativa, para os países membros, as práticas: (1) tratamento adequado aos direitos de voto; (2) tratamento justo de acionistas em hipótese de mudança no controle societário; (3) garantia de integridade dos relatórios financeiros e aperfeiçoamento da divulgação; (4) desenvolvimento de conselhos eficientes; (5) aprimoramento da qualidade, eficácia e segurança da estrutura jurídica e reguladora; e (6) cooperação contínua em âmbito regional. (OCDE, 2004)

Para Babic (2003), o desenvolvimento da governança corporativa requer o estabelecimento de regras de mercado para o crescimento econômico. A autora afirma que sem uma boa governança corporativa, as empresas não cumprem seus objetivos de lucratividade, responsabilidade social e eficácia operacional. O sucesso das empresas está atrelado às regras adequadas de governo, às instituições que as apoiam e à aceitação de uma cultura de governança corporativa entre os gestores, proprietários e outros stakeholders.

Segundo Leal e Saito (2003), há evidências de que a emissão de ADRs reduz o custo do capital próprio das empresas emitentes, pois a maior transparência exigida pelas instituições reguladoras dos EUA aliada ao sistema judiciário mais eficiente do país sinaliza menores riscos aos investidores.

Corroborando essa argumentação, o estudo de Lopes e Walker (2008), para empresas brasileiras no período de 1998 a 2004, constatou que práticas mais rigorosas de governança corporativa aliadas com a emissão de ADRs estão negativamente relacionadas com o gerenciamento de resultados. Para mensurar o grau de manipulação das informações, foi utilizada a metodologia de Leuz, Nanda e Wysocki (2003).

O trabalho de Leuz, Nanda e Wysocki (2003) consistiu em mensurar a transparência das informações divulgadas e relacioná-las com o sistema legal de proteção dos investidores, o enforcement legal, a maturidade do mercado e a concentração de propriedade. Os autores consideraram a manipulação dos lucros (Earnings Management - EM) como proxy para quantificar a transparência. A metodologia consistiu em mensurar quatro dimensões de manipulação dos resultados. A primeira dimensão (EM1) é a suavização dos lucros operacionais, calculada pela razão entre o desvio padrão da receita operacional líquida pelo desvio padrão do fluxo de caixa operacional. A segunda dimensão (EM2) representa a correlação entre as alterações nos componentes contábeis (accruals) com o fluxo de caixa operacional. A terceira dimensão (EM3) demonstra a magnitude calculada pela razão entre as variações das contas (accruals) em número absoluto pelo valor absoluto do fluxo de caixa. Por fim, a quarta dimensão (EM4) reflete o gerenciamento de pequenas perdas. A partir de uma média aritmética (EM) entre as quatro medidas individuais, os autores classificaram o grau de gerenciamento de resultados dos países e agruparam em três clusters. A pesquisa evidenciou que o gerenciamento de resultados diminui no grupo de países com forte proteção legal dos investidores, limitando a capacidade dos gestores em adquirir benefícios privados de controle.

Se de um lado a aderência aos padrões de governança corporativa possibilita uma melhor avaliação das ações da firma e, consequentemente, oportunidades de captação de recursos estrangeiros a custos mais baixos (SILVEIRA, 2005), é importante destacar que, por outro lado, conforme alerta Pereira (2013), algumas empresas optam pelo financiamento local, via endividamentos com bancos, mesmo a custos mais altos, para não alterarem suas práticas de governança. Os custos diretos e indiretos para a emissão de títulos e manutenção de uma empresa no mercado acionário também são fatores desmotivadores. (LEAL; SAITO, 2003)

Amaral et al. (2007) evidenciaram que as empresas brasileiras de capital aberto classificadas entre as maiores exportadoras e/ou com presença nos mercados de valores internacionais apresentam, na média, indicadores de qualidade de governança corporativa superiores aos das outras empresas. Para o estudo, os autores consideraram uma amostra de 128 empresas de capital aberto no período de 2003 a 2005 e construíram um índice de qualidade de governança composto por 20 perguntas binárias. Em seguida separaram as empresas 
em dois grupos, um composto por empresas consideradas atuantes internacionalmente (exportadoras ou que emitiram ADRs) e outro grupo com empresas não internacionalizáveis. Os autores concluíram, a partir de estatística descritiva, que a média do índice de governança corporativa era superior no grupo classificado como internacionalizado e concluíram que a inserção internacional pode ser uma das formas de melhorar a qualidade da governança e revelam que boas práticas de governança também podem ser um fator de competitividade para as empresas e contribuem para o desenvolvimento econômico do país.

O trabalho de Correia, Amaral e Louvet (2011) objetiva a construção de um índice capaz de quantificar a qualidade da governança nas empresas brasileiras $e$ validá-los mediante o confronto com resultados financeiros. Para o estudo, os autores consideraram as empresas de capital aberto não financeiras negociadas na BM\&FBOVESPA no período de 1997 a 2006. A partir de 19 indicadores de controle dos problemas de agência (métricos e não métricos) para cada organização e análise fatorial, os autores compuseram um índice da qualidade da governança. Para a validação do índice, agruparam os resultados em cinco clusters iguais, categorizando cada quintil que variou de "muito baixo" a "muito alto" e os relacionaram o desempenho financeiro das empresas. Concluíram que empresas com melhores práticas de governança possuem melhores resultados de valorização e relação risco-retorno.

Por outro lado, o estudo de Andrade e Galina apresentou relação inversa entre o grau de internacionalização e o desempenho das empresas multinacionais. Os autores avaliaram 33 empresas multinacionais de países em desenvolvimento, utilizaram como variável independente o DOI (composto pelo percentual de ativos externos, de vendas externas e funcionários externos), como variável dependente o desempenho financeiro (medido pelo retorno sobre ativos ROA) e como variáveis de controle o tamanho da multinacional, o tipo de indústria e o país de origem. Os autores concluíram que existe relação linear negativa entre a internacionalização e o desempenho e justificaram o fato argumentando que empresas podem buscar a internacionalização como meio para compensar as fra- quezas na gestão dos negócios, baixa competitividade local e práticas de governança corporativa deficientes.

Posto isso, supõe-se neste estudo, assim como nos trabalhos de Amaral et al. (2007), Lopes e Walker (2008) e Pereira e Sheng (2013), que empresas com melhores práticas de governança corporativa apresentem melhores indicadores de internacionalização como exportação e ADRs.

\section{Metodologia}

Esse trabalho é considerado quantitativo quanto à abordagem do problema e descritivo quanto aos objetivos, uma vez, que se pretende conhecer os efeitos da internacionalização na qualidade da governança corporativa e um possível efeito inverso.

Para o tratamento dos dados utilizou-se a metodologia de dados em painel. Segundo Fávero et al. (2009), dados em painel representam um conjunto de dados em que as unidades cross-section são disponibilizadas ao longo do tempo.

Inicialmente, a amostra foi formada pelas empresas de capital aberto com ações comercializadas na BM\&FBovespa, no período de 2005 a 2010, excluindo as instituições financeiras. Estas foram excluídas da amostra por apresentarem estrutura contábil e financeira muito peculiar, bem como critérios de análise diferentes de outros segmentos de negócio.

Conforme metodologia de Perobelli, Lopes e Silveira (2012) foram selecionadas as empresas com maiores níveis de liquidez. Essa seleção consiste em: 1 - identificar a empresa com maior liquidez no período analisado; 2 - multiplicar o resultado de liquidez dessa empresa por 0,001\%; e 3 - selecionar as empresas com resultados de liquidez superiores ao valor multiplicado. Assim, a amostra populacional do estudo envolveu 245 empresas, formando um painel não balanceado.

A Tabela 1 apresenta as características das empresas investigadas, discriminando-as com relação à ocorrência de exportação no período estudado e à adesão aos níveis de governança corporativa diferenciados da BM\&FBovespa (Nível 1, Nível 2 e Novo Mercado). 
Tabela 1: Comportamento das empresas analisadas em relação à ocorrência de exportação e à adesão aos níveis de governança corporativa da BM\&FBovespa

\begin{tabular}{|c|c|c|c|c|c|c|c|}
\hline \multirow[b]{2}{*}{ SEtor } & \multicolumn{3}{|c|}{ EMPRESAS COM EXPORTAÇÃo } & \multicolumn{3}{|c|}{ EMPRESAs SEm Exportação } & \multirow{2}{*}{$\begin{array}{c}\text { TotAL } \\
\text { AMOSTRA }\end{array}$} \\
\hline & $\begin{array}{c}\text { Mercado } \\
\text { Tradicional }\end{array}$ & $\begin{array}{l}\text { Com Nível } \\
\text { Governança }\end{array}$ & $\begin{array}{c}\text { Total Coм } \\
\text { Exp }\end{array}$ & $\begin{array}{c}\text { Mercado } \\
\text { Tradicional }\end{array}$ & $\begin{array}{l}\text { Com Nível } \\
\text { GovernançA }\end{array}$ & $\begin{array}{c}\text { Total } \\
\text { SEM ExP. }\end{array}$ & \\
\hline Consumo cíclico & 8 & 4 & 12 & 21 & 8 & 29 & 41 \\
\hline Construção; transporte & 1 & 7 & 8 & 15 & 16 & 31 & 39 \\
\hline Materiais básicos & 10 & 13 & 23 & 7 & 4 & 11 & 34 \\
\hline Utilidade pública & 0 & 1 & 1 & 18 & 14 & 32 & 33 \\
\hline Consumo não cíclico & 7 & 7 & 14 & 11 & 7 & 18 & 32 \\
\hline Bens industriais & 4 & 10 & 14 & 9 & 4 & 13 & 27 \\
\hline Telecomunicações & 0 & 0 & 0 & 11 & 1 & 12 & 12 \\
\hline Petróleo & 1 & 0 & 1 & 2 & 1 & 3 & 4 \\
\hline Outros & 0 & 1 & 1 & 8 & 14 & 22 & 23 \\
\hline Total & 31 & 43 & 74 & 102 & 69 & 171 & 245 \\
\hline
\end{tabular}

Fonte: Adaptada de Revista Exame (2013) e BM\&FBOVESPA (2014)

Para mensurar a qualidade da governança das empresas estudadas foi criado um índice de governança corporativa (IGC) a partir da análise fatorial de 11 variáveis, que compreendem quatro dimensões da governança corporativa: (1) qualidade do conselho de administração; (2) incentivos aos gestores; (3) transparência; e (4) estrutura de propriedade e controle. (CARVALHAL-DA-SILVA; LEAL, 2005; CORREIA, 2008; PEIXOTO, 2012)

No que tange à dimensão qualidade do conselho de administração, conforme Andrade et al. (2009) e Peixoto (2012), foram avaliadas: (1) o grau de independência do conselho, (2) a separação de funções entre presidente do conselho e CEO (Chief Executive Officer) e (3) o tamanho do conselho.

$\mathrm{O}$ grau de independência do conselho (GIC) foi calculado pela razão entre o número de conselheiros externos e o total de conselheiros. Dessa forma, o resultado pode variar de "zero" a "um", sendo "um" a melhor situação de independência. Já a variável separação de funções presidente/CEO (SEP_PC) é dicotômica, podendo assumir valor "zero" quando o presidente do conselho é o CEO da empresa e "um" quando há separação das funções (ANDRADE et al., 2009). Os dados para essas variáveis foram coletados nos IANs (Informativos Anuais) e Formulários de Re- ferência da Comissão de Valores Mobiliários (CVM). O tamanho do conselho é a quantidade total de membros conselheiros. Embora não exista na literatura um consenso sobre o tamanho ideal do conselho, neste estudo foi considerado que quanto maior o conselho menor as possibilidades de expropriação dos acionistas minoritários e consequentemente melhor a qualidade da governança corporativa. (HERMALIN; WEISBACH, 2003; SILVEIRA, 2005)

Para a dimensão incentivo aos gestores foram considerados: (1) a remuneração total; (2) a participação nos lucros; e (3) a possibilidade de compras de ações da companhia. É esperado que as empresas com melhores práticas de remuneração consigam reter os melhores gestores e desencorajar comportamentos oportunistas. Essa teoria é amparada nos estudos de Perobelli, Lopes e Silveira (2012), Correia (2008) e Peixoto (2012).

No que tange à remuneração paga aos executivos foi considerado o montante monetário total pago anualmente aos executivos da companhia. A participação nos lucros é uma variável dummy, assumindo valores "zero" para as empresas cuja política de remuneração não inclui participação dos gestores no lucro da firma $e$ "um" quando os gestores têm direito a parcela do lucro. O mesmo critério foi adotado para a existência de um 
plano de opções de compra de ações. As informações relativas à compensação dos gestores foram obtidas nos IANs e nos Formulários de Referência da CVM.

Para a dimensão transparência foram adotadas as proxies propostas por Leuz, Nanda e Wysocki (2003), que consideram o gerenciamento dos resultados (earnings mangement) como medida para avaliar a transparência da firma. Os estudos de Correia (2008) e Peixoto (2012) também consideraram essa metodologia para mensurar o mecanismo de transparência das empresas analisadas.

O método consiste em analisar a manipulação dos resultados segundo a ponderação de três dimensões: EM1, EM2 e EM3, sendo EM1 a suavização dos lucros operacionais, EM2 a correlação entre mudanças nas provisões contáveis (accruals) e o fluxo de caixa operacional e EM3 a magnitude das variações.

O cálculo dos acréscimos (accruals) e do fluxo de caixa operacional (CFO) são premissas para mensurar as dimensões EM1, EM2 e EM3 e correspondem às E1 e 2. No caso do fluxo de caixa operacional, embora a base de dados Economática apresente o resultado consolidado pelas empresas, optou-se pela fórmula (Equação 2) de Leuz, Nanda e Wysocki (2003).

$$
\begin{gathered}
A C C_{i t}=\left(\Delta C A_{i t}-\Delta C A S H_{i t}\right)-\left(\Delta C L_{i t}-\Delta S T D_{i t}-\Delta T P_{i t}\right)-D e p_{i t} \\
C F O_{i t}=L D I R_{i t}-A C C_{i t}
\end{gathered}
$$

Onde:

$A C C_{i t}=$ Accruals, alterações nos componentes contábeis dos lucros;

$\Delta C A_{i t}=$ Variação anual nos ativos circulantes totais;

$\triangle C A S H_{i t}=$ Variação anual no disponível e investimentos de curto prazo;

$\Delta C L_{i t}=$ Variação anual nos passivos circulantes totais; $\Delta S T D_{i t}=$ Variação anual na dívida de curto prazo incluída nos passivos circulantes;

$\Delta T P_{i t}=$ Variação anual no imposto de renda a pagar;

$D e p_{i t}=$ Despesa de depreciação e amortização;

$L D I R_{i t}=$ Lucro depois do imposto de renda;

$C F O_{i t}=$ Fluxo de caixa das operações.
No Quadro 2 são apresentadas as fórmulas para a composição da variável transparência. Para os cálculos extraíram-se os dados da base Economática.

Por fim, para avaliação da estrutura de propriedade e controle foram consideradas as variáveis direito de controle e direito sobre o fluxo de caixa. A variável direito de controle (DCONT) foi calculada pela razão do volume de ações ordinárias (ON) detido pelo acionista majoritário em relação ao total de ações ordinárias da firma, podendo variar de "zero" a "100\%", sendo " $100 \%$ " a situação extrema em termos de concentração de propriedade. Para a variável direito sobre o fluxo de caixa (DSFC) foi considerado o percentual de ações ordinárias e preferenciais em poder do acionista majoritário. Estudos apontam que empresas com menor concentração de propriedade, maior proteção aos acionistas minoritários, o que inclui direito de voto $e$ participação nas decisões da firma sinalizam melhores práticas de governança. (LA PORTA et al., 2002; KAPPLER; LOVE, 2002; CLAESSENS; LAEVEN, 2002;

\begin{tabular}{|c|c|c|}
\hline DimEnSÃo & Conceito & FóRMULA \\
\hline $\begin{array}{c}\text { EM1 } \\
\text { Suavização } \\
\text { dos lucros }\end{array}$ & $\begin{array}{l}\text { Relação entre o } \\
\text { desvio-padrão da } \\
\text { receita operacional } \\
\text { líquida e o desvio } \\
\text { padrão do fluxo de } \\
\text { caixa operacional }\end{array}$ & $E M 1=\frac{\sigma\left(L D I R_{i t}\right)}{\sigma\left(C F O_{i t}\right)}$ \\
\hline $\begin{array}{c}\text { EM2 } \\
\text { Correlação } \\
\text { entre as } \\
\text { medidas }\end{array}$ & $\begin{array}{l}\text { Correlação de } \\
\text { Spearman entre as } \\
\text { variações dos } \\
\text { accruals e as } \\
\text { variações do fluxo de } \\
\text { caixa operacional }\end{array}$ & $E M 2=\rho(\triangle A C C ; \triangle C F O)$ \\
\hline $\begin{array}{c}\text { EM3 } \\
\text { Magnitude } \\
\text { dos accruals }\end{array}$ & $\begin{array}{l}\text { Razão entre o valor } \\
\text { absoluto dos accruals } \\
e \text { fluxo de caixa } \\
\text { operacional }\end{array}$ & $E M 3=\frac{|A C C|}{|C F O|}$ \\
\hline
\end{tabular}
PEIXOTO, 2012; PEREIRA; SHENG, 2013)

Quadro 2: Proxies para cálculo do gerenciamento de resultados (earnings mangement)

Fonte: Leuz, Nanda e Wysocki (2003), Correia (2008) e Peixoto (2012)

No Quadro 3 é apresentado o resumo dos 11 indicadores que compuseram o índice de governança corporativa do presente estudo (IGC_11). Foi considerada ainda a análise fatorial dos cinco componentes mais representativos (IGC_5) e análise de um terceiro índice com o indicador de governança mais representativo e somente este (IGC_1). 
O índice de governança corporativa proposto foi elaborado a partir da técnica análise de componentes principais (ACP). De acordo com Fávero et al. (2009), a técnica consiste em calcular todas as correlações entre diversos indicadores e isolar o fator principal, ou seja, identificar um fator que represente um conjunto de variáveis inter-relacionadas. Nessa técnica são estimados os fatores e as variâncias, de modo que as co-variâncias ou as correlações estejam o mais próximo possível dos valores observados.

\begin{tabular}{|c|c|c|c|}
\hline Dimensão & INDICADOR & MEnsuração & Autores \\
\hline \multirow{3}{*}{$\begin{array}{l}\text { Conselho de } \\
\text { Administração }\end{array}$} & Grau de independência (GIC) & $\begin{array}{l}\text { Conselhos Independentes/ } \\
\text { Conselheiros totais }\end{array}$ & \multirow{3}{*}{$\begin{array}{l}\text { Hermalin e Weisbach (2003), } \\
\text { Andrade et al. (2009), Correia } \\
\text { (2008), Peixoto (2012) }\end{array}$} \\
\hline & $\begin{array}{l}\text { Independência do } \\
\text { presidente (SEP_PC) }\end{array}$ & $\begin{array}{l}\text { Dummy igual a "um" se } \\
\text { Presidente do conselho } \\
\text { é independente }\end{array}$ & \\
\hline & Tamanho do conselho (TCON) & Total de conselheiros & \\
\hline \multirow{3}{*}{$\begin{array}{l}\text { Compensação } \\
\text { dos gestores }\end{array}$} & $\begin{array}{l}\text { Remuneração dos } \\
\text { gestores (REM) }\end{array}$ & $\begin{array}{l}\text { Valor monetário anual } \\
\text { pago aos executivos }\end{array}$ & \multirow{3}{*}{$\begin{array}{l}\text { Perobelli, Lopes, Silveira (2012), } \\
\text { Correia (2008), Peixoto (2012) }\end{array}$} \\
\hline & Participação nos lucros (PART) & $\begin{array}{l}\text { Dummy igual a "um" se } \\
\text { existe participação nos lucros }\end{array}$ & \\
\hline & $\begin{array}{l}\text { Plano de opções de compra } \\
\text { de ações (ESOP) }\end{array}$ & $\begin{array}{l}\text { Dummy igual a "um" se existe } \\
\text { plano de compra de ações }\end{array}$ & \\
\hline \multirow{3}{*}{ Transparência } & Suavização dos lucros (EM1) & $E M 1=\frac{\sigma\left(L D I R_{i f}\right)}{\sigma\left(C F O_{i t}\right)}$ & \multirow{3}{*}{$\begin{array}{l}\text { Leuz, Nanda, Wysocki (2003), } \\
\text { Correia (2008), Peixoto (2012) }\end{array}$} \\
\hline & $\begin{array}{l}\text { Correlação entre as } \\
\text { medidas (EM2) }\end{array}$ & $E M 2=\rho(\triangle A C C ; \triangle C F O)$ & \\
\hline & Magnitude dos accruals (EM3) & $E M 3=\frac{|A C C|}{|C F O|}$ & \\
\hline \multirow{2}{*}{$\begin{array}{l}\text { Estrutura de } \\
\text { propriedade } \\
\text { e controle }\end{array}$} & Direito de controle (DCONT) & $\begin{array}{l}\text { Volume de ações ON } \\
\text { do acionista majoritário/ } \\
\text { Volume total de ON }\end{array}$ & \multirow{2}{*}{$\begin{array}{l}\text { La Porta et al. (2002), } \\
\text { Kappler e Love (2002), Correia (2008), } \\
\text { Peixoto (2012), Pereira e Sheng (2013) }\end{array}$} \\
\hline & $\begin{array}{l}\text { Direito sobre o fluxo } \\
\text { de caixa (DSFC) }\end{array}$ & $\begin{array}{l}\text { Volume de ações ON } \\
\text { e PN do acionista } \\
\text { majoritário/ Volume total }\end{array}$ & \\
\hline
\end{tabular}

Quadro 3: Resumo dos indicadores de governança corporativa para a construção do IGC pela Análise Fatorial (ACP) Fonte: Elaborado pelos autores deste artigo

No que se refere à internacionalização de uma empresa, Mansi e Reeb (2002) apontam que esta pode ser mensurada por três indicadores, que são os seguintes: exportações sobre vendas totais, ativos no exterior sobre ativos totais e distribuição geográfica, isto é, o número de países onde a empresa possui instalações.

Assim, seria possível utilizar esse modelo, com três medidas definindo o nível de internacionalização, assim como Pereira e Sheng (2013). No entanto, percebe-se nos estudos empíricos, grande dificuldade na obtenção desses dados para análise do grau de internacionalização, especialmente na obtenção dos ativos no exterior sobre os ativos totais e da distribuição geográfica. Além disso, segundo Mansi e Reeb (2002, p. 135), a correlação entre ativos no exterior sobre ativos totais e nível de exportação é de 0,89 e a correlação entre nível de exportação e distribuição geográfica é de 0,78 , o que significa que a associação entre os medidores é muito forte e positiva. 
Ancorado no argumento de Mansi e Reeb (2002, p. 134) que "[...] para o grau de atividade internacional da empresa (DOI), uma variável comumente utilizada é a proporção das vendas externas [...]", este estudo utilizou-se o índice de exportação sobre vendas e a comercialização de ações na bolsa de Nova York, para mensurar o grau de internacionalização das empresas no Brasil.

Por outro lado, o estudo de Andrade e Galina apresentou relação inversa entre o grau de internacionalização e o desempenho das empresas multinacionais. Os autores avaliaram 33 empresas multinacionais de países em desenvolvimento, utilizaram como variável independente o DOI (composto pelo percentual de ativos externos, de vendas externas e funcionários externos), como variável dependente o desempenho financeiro (medido pelo retorno sobre ativos $\mathrm{ROA}$ ) e como variáveis de controle o tamanho da multinacional, o tipo de indústria e o país de origem. Os autores concluíram que existe relação linear negativa entre a internacionalização e o desempenho e justificaram o fato argumentando que empresas podem buscar a internacionalização como meio para compensar as fraquezas na gestão dos negócios, baixa competitividade local e práticas de governança corporativa deficientes.

Como variáveis de controle, este estudo considerou o tamanho da firma (TAM), o crescimento da receita $(\mathrm{CR})$, o risco de falência (RISK), o pagamento de dividendos (PAYOUT) e a tangibilidade dos ativos (TANG).

O tamanho da firma (TAM) é obtido pelo logaritmo do ativo total. Não existe consenso em relação ao efeito (positivo ou negativo) sobre a qualidade da governança corporativa, já que de um lado existem argumentos que a complexidade da gestão em grandes empresas tendem a aumentar a assimetria de informações e por outro lado, apesar custo de monitoramento, empresas maiores tendem a manter melhores práticas de transparência já que estão mais susceptíveis a atenção dos analistas e agências de rating. (KLAPPER; LOVE, 2002; PEREIRA; SHENG, 2013)
O crescimento é medido pela variação anual da receita líquida. As empresas com maiores taxas de crescimento necessitam de maiores recursos para financiá-los e tendem a melhor qualidade da governança como forma de atrair investidores. Por outro lado, existem argumentos de que empresas com maiores taxas de crescimento necessitam de maiores recursos e, por isso, tendem a gerenciar os resultados como forma de reter recursos internos e diminuir o pagamento de dividendos. (IQUIAPAZA; LAMOUNIER; AMARAL, 2008; PEIXOTO, 2012)

$\mathrm{O}$ risco de falência mede a instabilidade dos fluxos de caixa da empresa. Calcula-se pelo logaritmo do desvio-padrão do lucro operacional dos últimos cinco anos e conforme Pereira e Sheng (2013) quanto maior o risco, maior tende a ser a concentração da propriedade e consequentemente pior a qualidade da governança corporativa.

No que se refere à tangibilidade dos ativos (TANG), é mensurado pela razão entre a soma dos ativos imobilizados pelo ativo total e pode apresentar relação positiva ou negativa com a governança corporativa. Empresas com grande concentração de ativos intangíveis podem melhorar a qualidade de sua governança com o propósito de aumentar a confiabilidade $e$ atrair investidores, por outro lado podem possuir maiores problemas em monitorar os recursos. (HIMMELBERG, et al., 1999; PEREIRA; SHENG, 2013)

Para o percentual de dividendos pagos anualmente aos acionistas em relação ao lucro líquido (PAYOUT) espera-se uma relação positiva com o índice de governança, uma vez que empresas com maiores pagamentos de dividendos tendem a possuir melhores práticas de governança. (LA PORTA, et al., 1998; IQUIAPAZA; LAMOUNIER; AMARAL, 2008; PEIXOTO, 2012; PEREIRA; SHENG, 2013)

O Quadro 4 resume as variáveis independentes, as dependentes $e$ as de controle consideradas nas regressões analisadas. 


\begin{tabular}{|c|c|c|c|c|}
\hline Sigla & $\begin{array}{c}\text { FoRMA DE } \\
\text { MENSURAÇÃo }\end{array}$ & $\begin{array}{c}\text { FoNTE COLETA } \\
\text { DADOS }\end{array}$ & $\begin{array}{c}\text { EFEITO } \\
\text { ESPERADO }\end{array}$ & Autores \\
\hline \multicolumn{5}{|c|}{ IGC como variável dependente } \\
\hline 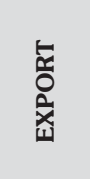 & $\begin{array}{l}\text { Percentual de } \\
\text { exportação } \\
\text { sobre receita }\end{array}$ & $\begin{array}{l}\text { Sítio eletrônico } \\
<\text { exame.abril. } \\
\text { com.br/ nego- } \\
\text { cios/melhores- } \\
\text {-e-maiores/> }\end{array}$ & + & 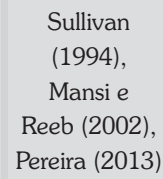 \\
\hline 奥 & $\begin{array}{l}\text { Dummy sendo } \\
\text { valor } 1 \text { se } \\
\text { a empresa } \\
\text { emite ações na } \\
\text { Bolsa de NY, } \\
\text { níveis } 2 \text { e } 3\end{array}$ & CVM (2013) & + & $\begin{array}{c}\text { Correia } \\
\text { (2008), } \\
\text { Lameira } \\
\text { (2012), Pei- } \\
\text { xoto (2012) }\end{array}$ \\
\hline \multicolumn{5}{|c|}{ EXPORT como variável dependente } \\
\hline $\begin{array}{l}z \\
\underbrace{\prime}_{0} \\
0\end{array}$ & $\begin{array}{c}\text { Análise } \\
\text { Fatorial das } \\
\text { onze variáveis } \\
\text { de governança }\end{array}$ & $\begin{array}{c}\text { CVM e } \\
\text { Economática }\end{array}$ & + & Pereira (2013) \\
\hline 㣢 & $\begin{array}{l}\text { Análise Fato- } \\
\text { rial das cinco } \\
\text { variáveis de } \\
\text { governança }\end{array}$ & $\begin{array}{c}\text { CVM e } \\
\text { Economática }\end{array}$ & + & Pereira (2013) \\
\hline "ي & $\begin{array}{l}\text { Análise Fato- } \\
\text { rial da variável } \\
\text { de gover- } \\
\text { nança mais } \\
\text { significativa }\end{array}$ & $\begin{array}{c}\text { CVMe } \\
\text { Economática }\end{array}$ & + & Pereira (2013) \\
\hline \multicolumn{5}{|c|}{ Controle } \\
\hline$\sum_{\xi}$ & $\begin{array}{l}\text { Logaritmo } \\
\text { natural do } \\
\text { ativo total }\end{array}$ & Economática & $+1-$ & $\begin{array}{c}\text { Klapper e } \\
\text { Love (2002), } \\
\text { Pereira (2013) }\end{array}$ \\
\hline 穵 & $\begin{array}{l}\text { Percentual de } \\
\text { crescimento } \\
\text { da receita } \\
\text { operacional }\end{array}$ & Economática & - & $\begin{array}{l}\text { Iquiapaza, } \\
\text { Lamounier, } \\
\text { Amaral } \\
\text { (2008), Pei- } \\
\text { xoto (2012) }\end{array}$ \\
\hline 感 & $\begin{array}{l}\text { log do desvio- } \\
\text {-padrão do } \\
\text { lucro ope- } \\
\text { racional dos } \\
\text { últimos } 5 \text { anos }\end{array}$ & Economática & - & Pereira (2013) \\
\hline 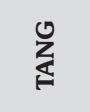 & $\begin{array}{c}\text { Ativos } \\
\text { Imobilizados/ } \\
\text { tivo Total }\end{array}$ & Economática & $+1-$ & $\begin{array}{c}\text { Pereira e } \\
\text { Sheng (2013) }\end{array}$ \\
\hline 占 & $\begin{array}{l}\text { Total de divi- } \\
\text { dendos pagos/ } \\
\text { lucro líquido } \\
\text { do exercício }\end{array}$ & Economática & + & $\begin{array}{l}\text { Iquiapaza, } \\
\text { Lamounier, } \\
\text { Amaral } \\
\text { (2008), Pei- } \\
\text { xoto (2012), } \\
\text { Pereira (2013) }\end{array}$ \\
\hline
\end{tabular}

Quadro 4: Variáveis independentes e de controle analisadas nos modelos econométricos Fonte: Elaborado pelos autores deste artigo

\subsection{Modelo Econométrico}

Neste estudo, será analisado em um primeiro momento o efeito da internacionalização sobre as práticas de governança corporativa (Modelo 1). Na sequência, será analisado o efeito da governança corporativa sobre a internacionalização (Modelo 2).

Primeiramente, será verificado através do teste de Breusch Pagan se há heterogeneidade nas unidades cross-section. Caso positivo, será utilizado o Modelo de Regressão com dados em Painel e o Teste de Hausman para verificar se o modelo mais adequado é o de efeitos fixos ou aleatórios.

Nessa perspectiva, o modelo a ser testado considera a governança corporativa como variável dependente, sendo exportação e emissão de ADRs as variáveis de teste do modelo.

A variável dependente qualidade da governança corporativa é mensurada pelos índices de qualidade de governança corporativa IGC. No caso deste trabalho foram três os IGC, a saber: IGC1, IGC5 e IGC11. Portanto, a partir do Modelo 1 há três equações de regressão, uma para cada variável dependente.

Já as variáveis TAM, CR, RISK, TANG e PAYOUT foram extraídas a partir da literatura como variáveis com função de controle da relação entre internacionalização e governança corporativa.

$$
\begin{aligned}
& \mathrm{IGC}_{\text {it }}=\alpha_{1}+\beta_{1} \mathrm{EXP}_{\text {it }}+\beta_{2} \mathrm{ADR}_{\mathrm{it}}+\beta_{3} \mathrm{TAM}_{\mathrm{it}}+\beta_{4} \mathrm{CR}_{\mathrm{it}}+ \\
& \beta_{5} \mathrm{RISK}_{\mathrm{it}}+\beta_{6} \mathrm{TANG}_{\mathrm{it}}+\beta_{7} \mathrm{PAYOUT}_{\mathrm{it}}+\varepsilon_{\mathrm{it}} \\
& \text { (Modelo 1) }
\end{aligned}
$$

No segundo modelo, a variável exportação é a dependente, e o IGC passa a ser a variável teste. Assim como no Modelo 1, haverá três equações, uma para cada índice.

$\mathrm{EXP}_{\mathrm{it}}=\alpha_{1}+\beta_{1} \mathrm{IGC}_{\mathrm{it}}+\beta_{2} \mathrm{ADR}+\beta_{3} \mathrm{TAM}_{\mathrm{it}}+\beta_{4} \mathrm{CR}_{\mathrm{it}}+$ $\beta_{5}$ RISK $_{\mathrm{it}}+\beta_{6} \mathrm{TANG}_{\mathrm{it}}+\beta_{7} \mathrm{PAYOUT}_{\mathrm{it}}+\varepsilon_{\mathrm{it}}$ (Modelo 2)

\subsection{Resultados Empíricos e Discussão}

A Figura 2 apresenta a trajetória anual das empresas da amostra em relação ao número de empresas exportadoras ou não exportadoras. No período analisado observa-se que existe uma tendência de aumento das empresas que exportam, em contrapartida evidencia- 
-se uma tendência de diminuição das empresas que não exportam.

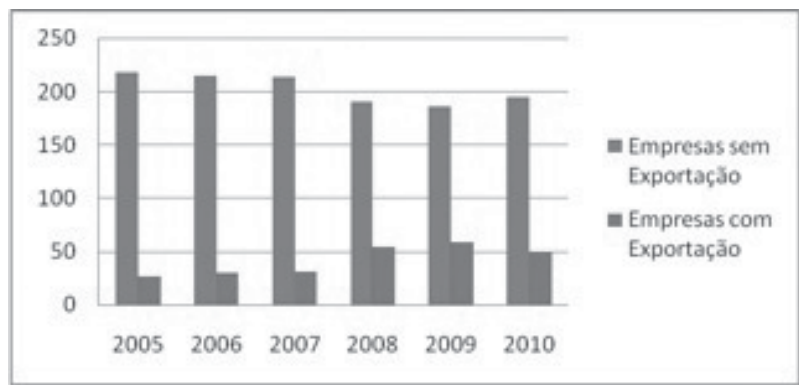

Figura 2: Trajetória da exportação nas empresas avaliadas Fonte: Adaptada de Revista Exame (2013)

No que diz respeito à construção do índice de governança, a Tabela 2 apresenta uma análise descritiva dos indicadores que compuseram o índice. No período analisado, a maioria das empresas (60\%) apresentou presidente do conselho diferente do CEO da empresa. No quesito remuneração, evidenciou-se que $43 \%$ das empresas possuem como política de remuneração a participação nos lucros e apenas $29 \%$ possuem plano de opções de compra de ações. Embora o desvio-padrão do mecanismo remuneração (REM) tenha sido maior que a média, esse fato se justifica pelas diferenças entre os tamanhos das empresas, número de funcionários e consequentemente número de membros executivos.
Tabela 2: Análise descritiva dos indicadores de governança corporativa no período de 2005 a 2010

\begin{tabular}{|c|c|c|c|c|c|}
\hline & $\begin{array}{c}\text { OBser- } \\
\text { vações }\end{array}$ & Média & $\begin{array}{c}\text { MínI- } \\
\text { Mo }\end{array}$ & $\begin{array}{c}\text { MÁxI- } \\
\text { Mo }\end{array}$ & DESvio \\
\hline GIC & 1.375 & 0,57 & 0 & 1 & 0,16 \\
\hline SEP_PC & 1.374 & $64 \%$ & - & - & - \\
\hline TCON & 1.375 & 12,36 & 1 & 41 & 6,47 \\
\hline REM & 1.287 & 6.862 mil & 5.508 & 97.423 & 9.910 \\
\hline PART & 1.374 & $43 \%$ & - & - & - \\
\hline ESOP & 1.374 & $29 \%$ & - & - & - \\
\hline EM1 & 1.416 & 0,76 & 0,04 & 5,44 & 0,60 \\
\hline EM2 & 1.371 & $-0,6$ & $-1,00$ & 1,00 & 0,49 \\
\hline EM3 & 1.279 & 1,01 & $-1,00$ & 27,86 & 2,09 \\
\hline DCONT & 1.367 & $47,36 \%$ & 0 & 99,86 & 25,99 \\
\hline DSFC & 1.357 & $38,72 \%$ & 0 & 100 & 22,08 \\
\hline
\end{tabular}

Fonte: Dados da pesquisa

A Tabela 3 mostra o resultado da correlação entre os indicadores componentes do IGC_11. As altas correlações (acima de 0,30) atendem aos requisitos iniciais para a aplicação da técnica da análise fatorial (FÁVERO et al., 2009). Além de agrupar as variáveis em um índice, a análise fatorial foi utilizada para evitar os problemas de multicolinearidade.

Tabela 3: Matriz de correlação entre as variáveis de Governança Corporativa no período de 2005 a 2010

\begin{tabular}{|c|c|c|c|c|c|c|c|c|c|c|c|}
\hline & GIC & SEP_PC & TCON & REM & PART & ESOP & EM1 & EM2 & EM3 & DCONT & DSFC \\
\hline GIC & 1 & & & & & & & & & & \\
\hline SEP_PC & 0,253 & 1 & & & & & & & & & \\
\hline TCON & 0,238 & 0,293 & 1 & & & & & & & & \\
\hline REM & $-0,006$ & 0,11 & 0,432 & 1 & & & & & & & \\
\hline PART & $-0,019$ & 0,060 & 0,099 & 0,098 & 1 & & & & & & \\
\hline ESOP & $-0,024$ & 0,094 & 0,176 & 0,255 & 0,077 & 1 & & & & & \\
\hline EM1 & $-0,043$ & 0,003 & $-0,091$ & $-0,037$ & $-0,082$ & $-0,054$ & 1 & & & & \\
\hline EM2 & $-0,055$ & $-0,032$ & $-0,28$ & 0,039 & 0,003 & 0,061 & 0,455 & 1 & & & \\
\hline EM3 & 0,006 & 0,024 & 0,026 & $-0,002$ & 0,010 & 0,023 & 0,011 & $-0,027$ & 1 & & \\
\hline DCONT & 0,009 & 0,013 & 0,102 & 0,105 & 0,053 & 0,263 & $-0,107$ & $-0,065$ & $-0,012$ & 1 & \\
\hline DSFC & $-0,092$ & $-0,027$ & $-0,167$ & $-0,126$ & $-0,133$ & $-0,142$ & 0,100 & 0,039 & 0,002 & $-0,694$ & 1 \\
\hline
\end{tabular}

Fonte: Dados da pesquisa 
A análise descritiva das variáveis de controle é apresentada na tabela 4. No que tange às exportações, cabe salientar que a média do volume de exportação em relação à receita, quando considerado somente as 74 empresas exportadoras, é de $24,4 \%$. Porém, quando são incluídas todas as empresas (exportadoras ou não), a média de exportação cai para $4,15 \%$, uma vez que, às empresas que não exportam é atribuído o valor "zero". Com relação à emissão de ADR, foram atribuídos valores iguais a "um", no ano em que ocorreu emissão de ADR pela empresa. A incidência de valores iguais a "um", ou seja, com a presença de emissão de ADR foi de 188 no período avaliado, ou seja, aproximadamente $13 \%$ da amostra.

Tabela 4: Análise Descritiva das Variáveis do Estudo

\begin{tabular}{|c|c|c|c|c|c|}
\hline VARIÁVEL & UNIDADE & QuANTIDADE DE DADOS & MÉDIA & Mínimo & MÁximo \\
\hline Exportação & Percentual & 1470 & 4,15 & 0 & 100 \\
\hline Ativo & Milhares & 1288 & 11.447 .823 & 109 & 834.742 .280 \\
\hline Crescimento da Receita & Percentual & 1164 & 16 & -96 & 669 \\
\hline Desvio do Lucro Líquido & Milhares & 1236 & 292.581 & 135 & 8.803 .783 \\
\hline Payout & Índice & 1275 & 0,26 & $-4,7$ & 4,97 \\
\hline \multirow[t]{2}{*}{ Tangibilidade dos Ativos } & Percentual & 1249 & 32,03 & 0,02 & 90,89 \\
\hline & & & \multicolumn{3}{|c|}{ Presença de emissão de ADR } \\
\hline Emissão ADR & Dummy & 1470 & \multicolumn{3}{|c|}{188} \\
\hline
\end{tabular}

Fonte: Dados da pesquisa

Após a composição do IGC pela análise fatorial, cumpre avaliar o comportamento do índice mediante as variáveis de internacionalização e de controle. A Tabela 5 apresenta o resultado das correlações dessas variáveis.

A variável exportação (EXPORT) apresentou correlações positivas com o IGC_5 e IGC_1, o que sinaliza que empresas com boas práticas de governança corporativa tendem a possuir melhores oportunidades de internacionalização via volume de exportações realizadas, ou que quanto mais internacionalizada for a empresa, melhores são as práticas de governança.
Essas oportunidades podem decorrer de melhores condições de preços, melhor confiabilidade nas negociações, melhor qualidade dos produtos e melhor credibilidade da empresa.

O tamanho da firma foi a variável que apresentou correlações mais altas com a maioria das outras variáveis analisadas, evidenciando que o tamanho da empresa tem uma alta associação com a governança corporativa e as práticas de internacionalização. Esse resultado também foi observado nos estudos de Kappler e Love (2002), Peixoto (2012), Pereira e Sheng (2013).

Tabela 5: Matriz de correlação entre as variáveis dependentes, independentes e de controle dos modelos econométricos

\begin{tabular}{|c|c|c|c|c|c|c|c|c|c|c|}
\hline & IGC_11 & IGC_5 & IGC_1 & EXPORT & ADR & TAM & CR & RISK & TANG & PAYOUT \\
\hline IGC_11 & 1 & & & & & & & & & \\
\hline IGC_5 & 0,559 & 1 & & & & & & & & \\
\hline IGC_1 & 0,381 & 0,656 & 1 & & & & & & & \\
\hline EXPORT & 0,214 & 0,322 & 0,370 & 1 & & & & & & \\
\hline ADR & 0,005 & $-0,029$ & $-0,001$ & 0,105 & 1 & & & & & \\
\hline TAM & 0,256 & 0,348 & 0,345 & 0,317 & 0,052 & 1 & & & & \\
\hline $\mathrm{CR}$ & 0,075 & 0,001 & $-0,014$ & $-0,014$ & 0,140 & 0,205 & 1 & & & \\
\hline RISK & 0,141 & 0,209 & 0,194 & 0,147 & 0,011 & 0,669 & 0,238 & 1 & & \\
\hline TANG & 0,068 & 0,096 & 0,161 & 0,001 & 0,0697 & $-0,108$ & $-0,039$ & $-0,154$ & 1 & \\
\hline PAYOUT & $-0,048$ & $-0,001$ & $-0,092$ & $-0,050$ & $-0,034$ & 0,002 & $-0,003$ & $-0,025$ & $-0,026$ & 1 \\
\hline
\end{tabular}

Fonte: Dados da pesquisa 
Após a análise fatorial e utilizando a modelagem de dados em painel, os índices de governança obtidos foram regredidos com as variáveis dependentes e de controle pelo método dos Mínimos Quadrados Ordinários, posteriormente com o modelo de efeitos fixos e em seguida com o modelo de efeitos aleatórios.

Por meio do resultado do teste de Multiplicador de Lagrange (LM) e de Breusch-Pagan, verificou-se que houve rejeição da hipótese nula, a de que a variância dos resíduos seja igual a zero. Neste caso, para os dados deste estudo, a modelagem em painel é mais adequada do que o uso de MQO. Em seguida, aplicou-se o teste de Hausman que compara o resultado dos modelos de efeitos fixos com os de efeitos aleatórios. O resultado do teste mostra que não houve rejeição da hipótese nula, ou seja, o modelo de efeitos aleatórios é o que deve ser utilizado. Os testes de heterocedasticidade e autocorrelação comprovaram a necessidade de correções pela estimação com erros-padrão robustos.

A hipótese principal do trabalho é de que existe uma relação entre a internacionalização, representada neste estudo pelo percentual de exportação e emissão de ADRs nível 2 e 3, com a qualidade da governança corporativa. Essa hipótese verificou-se apenas quando considerado o IGC_5 e IGC_1, uma vez que para o IGC_11 não apresentou significância estatística, conforme Tabela 6.

No caso das exportações, o sinal positivo para a principal relação estudada corrobora a literatura sobre o tema, evidenciando que quanto maior o grau de exportações melhor tende a ser a qualidade da governança corporativa (SULLIVAN, 1994; MANSI; REEB, 2002; PEREIRA, 2013). Em suma, pode-se inferir que empresas mais internacionalizadas tendem a enfrentar maiores problemas de monitoramento dos gestores de suas operações fora do país. A empresa ao se internacionalizar, na média, aumenta de tamanho (aumento do faturamento e/ou ativos) e sua complexidade de gestão fazendo com que seus problemas de agência possam aumentar (PEREIRA, 2013). Portanto, a internacionalização pode trazer efeitos colaterais como a necessidade de aumento dos custos de agência para monitoramento das atividades dos gestores (BARCELOS, 2010). Logo, ao se internacionalizarem as empresas tendem a melhorar sua governança para evitar maiores gastos com custos de agência e aproveitarem melhor os benefícios da internacionalização (PEREIRA,
Tabela 6: Resultados das Regressões por Efeitos Aleatórios (Modelo 1)

\begin{tabular}{|c|c|c|c|}
\hline & $\begin{array}{c}\text { IGC_11 } \\
\text { COEFICIEN- } \\
\text { TE } \\
\text { P> }|\mathrm{z}|\end{array}$ & $\begin{array}{c}\text { IGC_5 } \\
\text { COEFICIEN- } \\
\text { TE } \\
\text { P> }|\mathrm{z}|\end{array}$ & $\begin{array}{c}\text { IGC_1 } \\
\text { COEFICIEN- } \\
\text { TE } \\
\text { P> }|\mathrm{z}|\end{array}$ \\
\hline EXPORT & $\begin{array}{c}0,0007235 \\
0,319\end{array}$ & $\begin{array}{c}0,0014076^{* *} \\
0,028\end{array}$ & $\begin{array}{c}0,0021666^{* * * *} \\
0,006\end{array}$ \\
\hline ADR & $\begin{array}{c}-0,0086062 \\
0,767\end{array}$ & $\begin{array}{c}-0,0247935^{* * *} \\
0,0281\end{array}$ & $\begin{array}{c}-0,0441969 * * \\
0,023\end{array}$ \\
\hline TAM & $\begin{array}{c}0,0270547^{* * * *} \\
0,004\end{array}$ & $\begin{array}{c}0,0239778^{* *} \\
0,022\end{array}$ & $\begin{array}{c}0,0256085^{*} \\
0,053\end{array}$ \\
\hline $\mathrm{CR}$ & $\begin{array}{c}1,94 e-09^{* *} \\
0,010\end{array}$ & $\begin{array}{c}2,06 e-10 \\
0,772\end{array}$ & $\begin{array}{c}2,84 e-10 \\
0,308\end{array}$ \\
\hline RISK & $\begin{array}{c}-8,20 e-09 \\
0,562\end{array}$ & $\begin{array}{c}1,08 e-09 \\
0,936\end{array}$ & $\begin{array}{c}1,63 e-09 \\
0,900\end{array}$ \\
\hline TANG & $\begin{array}{c}0,0025633 \\
0,188\end{array}$ & $\begin{array}{c}0,0044906^{* * * *} \\
0,003\end{array}$ & $\begin{array}{c}0,0089334 * * * \\
0,000\end{array}$ \\
\hline PAYOUT & $\begin{array}{c}-5,11 e-06^{* * *} \\
0,000\end{array}$ & $\begin{array}{c}4,34 e-06^{* * * *} \\
0,000\end{array}$ & $\begin{array}{c}2,81 e-06^{* * * *} \\
0,000\end{array}$ \\
\hline Constante & $\begin{array}{c}0,0328301 \\
0,818\end{array}$ & $\begin{array}{c}0,0196112 \\
0,898\end{array}$ & $\begin{array}{c}0,659176 \\
0,735\end{array}$ \\
\hline $\mathrm{R} 2$ & 12,9 & 12,9 & 18,02 \\
\hline Hausman & 0,2577 & 0,2577 & 0,5717 \\
\hline Breusch Pagan & 0,0002 & 0,0002 & 0,0000 \\
\hline Heterocedasticidade & 0,0000 & 0,0000 & 0,0000 \\
\hline Wooldridge & 0,7154 & 0,7154 & 0,0000 \\
\hline
\end{tabular}

Significância: * $10 \%$; ** $5 \%$; ** $1 \%$

Fonte: Dados da pesquisa

2013). Isso porque empresas bem governadas tendem a reduzir os custos de transação e, consequentemente, diminuir os preços de transferência, obter melhores condições de negociação, reduzir os riscos de atrasos de entrega e problemas de qualidade, aumentar a transparência das operações, entre outras vantagens adjacentes. (PEIXOTO, 2012)

Para a questão das ADRs, o sinal negativo contraria os estudos predominantes acerca do tema, pois é esperado que a comercialização de títulos no mercado financeiro norte-americano se relacione diretamente com a qualidade da governança corporativa, já que 
tende a proporcionar uma imagem de maior transparência para a empresa (DOIGE, et al., 2005). Por outro lado, o resultado de relação negativa corrobora o trabalho de Andrade e Galina (2013), o qual argumenta que empresas com fraca governança corporativa e baixo desempenho financeiro necessitam de obter recursos no exterior para compensar a ineficiência da gestão. A emissão de títulos no exterior, em especial ADRs nível 2 e 3, é um processo oneroso para as empresas, pois além do próprio custo da emissão, existem os custos de adequação da governança. Dessa forma, as empresas nacionais tendem a buscar recursos no exterior, via emissão de títulos, somente quando as possibilidades de recursos de financiamento interno estão esgotadas. A dificuldade de financiamento nacional pode decorrer, dentre outros motivos, de problemas internos de governança. E dado que empresas internacionais tendem a possuir maiores níveis de governança, o acesso a recursos no mercado de capitais do país de origem tende a ser mais barato (LEAL; SAITO, 2003), evitando assim a necessidade de emissão de ADR para captação de recursos mais onerosos para a firma.

A separação entre as variáveis exportações $e$ ADRs, neste estudo, contribui para evidenciar comportamentos antagônicos em relação à qualidade da governança corporativa, fato que não seria possível evidenciar, caso se utilizassem indicadores conjuntos de internacionalização, tais como o DOI.

A variável de controle tamanho da firma (TAM) apresentou relação positiva e significativa com a qualidade da governança. Esse fato comprova os argumentos de Klapper e Love (2002) e de Pereira e Sheng (2013), os quais afirmam que empresas maiores tendem a manter melhores práticas de transparência já que estão mais susceptíveis à atenção dos analistas e agências de rating.

No que diz respeito ao crescimento da receita (CR), o sinal positivo e significativo para o IGC_11 comprova a teoria de que empresas com expansão no volume de negócios tendem a apresentar melhores níveis de governança como forma de atrair investimentos externos. (PEIXOTO, 2012)
A variável de controle risco de falência (RISK) não apresentou significância em nenhum dos modelos testados.

O resultado positivo da relação da tangibilidade dos ativos (TANG) com IGC apresentou significância somente para os modelos IGC_5 e IGC_1 e evidenciou a teoria de que companhias com grande concentração de ativos tangíveis possuem naturalmente melhor qualidade da governança, pois por meio de seus ativos conseguem maior confiabilidade e atração junto aos investidores, conforme Pereira e Sheng (2013). Esse argumento, de acordo com Himmelberg et al. (1999) se baseia no fato de que quanto mais intangível for a atividade da empresa, maior será o risco de os recursos serem desviados (mais difícil é a monitoração dos investimentos nos ativos intangíveis), sendo que a relação inversa também ocorre.

No caso da associação entre o pagamento de dividendos (PAYOUT) e a qualidade de governança corporativa, o resultado mostrou-se distinto quando se comparam os três tipos de índice. No caso do IGC_11, o sinal da relação foi negativo, e para os outros dois índices positivo. Para os modelos com IGC_5 e IGC_1, pode-se dizer que o comportamento foi de acordo com a literatura (LA PORTA et al., 1998), indicando que quanto maior a distribuição de lucros aos acionistas, melhor será a proteção aos acionistas minoritários e melhor a qualidade da governança corporativa.

Após a análise do Modelo 1, cabe observar a relação da internacionalização frente às variações de qualidade da governança corporativa. Para isso, a exportação foi considerada a variável dependente e os IGCs como as variáveis independentes no modelo.

Novamente, foram testadas as regressões pelo método dos Mínimos Quadrados Ordinários, posteriormente com o modelo de efeitos fixos e aleatórios e os testes indicaram que o modelo de efeitos aleatórios é o mais adequado, bem como a necessidade de estimativas com erros-padrão robustos. Os resultados são apresentados na Tabela 7. 
Tabela 7: Resultados das Regressões por Efeitos Aleatórios (Modelo 2)

\begin{tabular}{|c|c|c|c|}
\hline & $\begin{array}{c}\text { EXPORT } \\
\text { COEFICIENTE } \\
\quad P>|z|\end{array}$ & $\begin{array}{c}\text { EXPORT } \\
\text { COEFICIENTE } \\
\text { P }>|z|\end{array}$ & $\begin{array}{c}\text { EXPORT } \\
\text { COEFICIENTE } \\
\text { P }>|z|\end{array}$ \\
\hline IGC_11 & $\begin{array}{c}7,2125 \\
0,005^{* *}\end{array}$ & & \\
\hline IGC_5 & & $\begin{array}{l}8,8997 \\
0,010^{*}\end{array}$ & \\
\hline IGC_1 & & & $\begin{array}{c}11,168 \\
0,041\end{array}$ \\
\hline $\mathrm{ADR}$ & $\begin{array}{c}-0,9673 \\
0,459\end{array}$ & $\begin{array}{c}-0,8223 \\
0,493\end{array}$ & $\begin{array}{c}-0,4344 \\
0,748\end{array}$ \\
\hline TAM & $\begin{array}{c}0,3518 \\
0,844\end{array}$ & $\begin{array}{c}0,7386 \\
0,691\end{array}$ & $\begin{array}{c}0,5297 \\
0,778\end{array}$ \\
\hline $\mathrm{CR}$ & $\begin{array}{c}-4,40 e-08 \\
0,500\end{array}$ & $\begin{array}{c}-3,10 e-08 \\
0,624\end{array}$ & $\begin{array}{c}-2,87 e-08 \\
0,657\end{array}$ \\
\hline RISK & $\begin{array}{c}9,46 e-07 \\
0,239\end{array}$ & $\begin{array}{c}8,58 e-07 \\
0,307\end{array}$ & $\begin{array}{c}7,55 e-07 \\
0,368\end{array}$ \\
\hline TANG & $\begin{array}{c}0,1403 \\
0,612\end{array}$ & $\begin{array}{c}0,1306 \\
0655\end{array}$ & $\begin{array}{c}0,0091 \\
0,975\end{array}$ \\
\hline PAYOUT & $\begin{array}{c}1,73 e-06 \\
0,955\end{array}$ & $\begin{array}{c}-0,0001 \\
0,013\end{array}$ & $\begin{array}{c}-0,000094 \\
0,031\end{array}$ \\
\hline Constante & $\begin{array}{c}11,917 \\
0,660\end{array}$ & $\begin{array}{c}5,7119 \\
0,840\end{array}$ & $\begin{array}{c}7,7226 \\
0,805\end{array}$ \\
\hline $\mathrm{R} 2$ & 3,81 & 8,07 & 11,9 \\
\hline Hausman & 0,1264 & $-9,840$ & 0,1368 \\
\hline Breusch Pagan & 0,0000 & 0,0000 & 0,0000 \\
\hline $\begin{array}{l}\text { Heteroce- } \\
\text { dasticidade }\end{array}$ & 0,0000 & 0,0000 & 0,0000 \\
\hline Wooldridge & 0,3150 & 0,3580 & 0,3686 \\
\hline
\end{tabular}

Significância: * $10 \%$; * $5 \%$; *** $1 \%$

Fonte: Dados da pesquisa

Da mesma forma que no Modelo 1, foi observada uma relação positiva entre o percentual de exportação $e$ as melhores práticas de governança. Esse resultado comprova a principal hipótese levantada, qual seja, a de que o nível de governança corporativa tem efeito positivo sobre a internacionalização, para os modelos considerando o IGC_11 e o IGC_5, corroborando os estudos de Pereira e Sheng (2013). Com isso, são cumpridos os objetivos deste estudo e comprovadas suas principais hipóteses.

No Modelo 2, ao se colocar a variável proxy de internacionalização (exportação) como variável dependente e os índices de governança como variáveis independentes, evidencia-se que o efeito reverso também é válido, ou seja, que uma maior governança pode explicar maiores níveis de internacionalização, como comentado anteriormente.

No entanto, os resultados evidenciam que, considerando as variáveis de controle selecionadas neste estudo (tamanho, crescimento da receita, risco, tangibilidade do ativo e payout), nenhuma possui relação significante com o percentual de exportação. Isso implica afirmar que, no segundo modelo econométrico analisado, a qualidade da governança corporativa é a variável que melhor explica as variações da exportação e/ou que há variáveis omitidas que podem estar influenciando esta relação, mas que ainda não foram identificadas. Além disso, pode-se inferir que o Modelo 1 apresentou melhor ajuste e especificação que o Modelo 2, na busca da relação entre governança e internacionalização.

\section{Considerações Finais}

Este estudo teve como principal objetivo analisar as relações entre internacionalização e qualidade da governança corporativa. As hipóteses iniciais foram ancoradas na teoria de que existe uma relação positiva entre as duas variáveis, ou seja, a internacionalização tem efeito positivo sobre a qualidade da governança corporativa, $e$ as boas práticas de governança favorecem a internacionalização das firmas.

O objeto de estudo envolveu uma amostra de 245 empresas brasileiras de capital aberto não financeiras, no período de 2005 a 2010. A qualidade da governança corporativa foi medida por índices construídos pelo método da Análise Fatorial (ACP) de 11 componentes dos mecanismos de governança, assim como nos trabalhos de Correia (2008) e Peixoto (2012). Para medir a internacionalização foram consideradas as variáveis exportação e emissão de ADRs níveis 2 e 3. O tratamento dos dados se deu por meio do Modelo de Regressão com dados em painel de efeitos aleatórios e 
com correção de heterocedasticidade e autocorrelação pelos erros-padrão robustos.

A primeira etapa do trabalho avaliou o efeito da internacionalização sobre o nível da governança corporativa. Os resultados evidenciaram que o percentual de exportações tem relação positiva com a qualidade da governança, assim como nos trabalhos de Sullivan (1994), Mansi e Reeb (2002) e Pereira (2013). Para a variável $\mathrm{ADR}$, a relação negativa contraria alguns estudos acerca do tema, pois é esperado que a comercialização de títulos no mercado financeiro norte-americano se relacione diretamente com a qualidade da governança corporativa (IQUIAPAZA; LAMOUNIER; AMARAL, 2008; LAMEIRA, 2012). Por outro lado, o resultado de relação inversa entre IGC e ADR corrobora o trabalho de Andrade e Galina (2013), o qual argumenta que empresas necessitam buscar financiamento no exterior para mitigar os efeitos de uma governança corporativa insuficiente, baixo desempenho financeiro e problemas de gestão. Dessa forma, buscar recursos em países estrangeiros é uma forma de compensar a ineficiência da gestão interna e uma necessidade para continuidade das operações.

As variáveis tamanho da firma e crescimento da receita apresentaram resultados positivos e significativos, fortalecendo o argumento de que empresas maiores tendem a manter as boas práticas de governança, pois estão mais susceptíveis à ação dos stakeholders externos e no caso do crescimento da receita comprova a teoria de que empresas com expansão no volume de negócios tendem a apresentar melhores níveis de governança como forma de atrair investimentos externos. (KLAPPER; LOVE, 2002; IQUIAPAZA; LAMOUNIER; AMARAL, 2008; PEIXOTO, 2012; PEREIRA; SHENG, 2013)

A segunda fase do estudo considerou a variável nível de exportação como dependente para analisar o efeito da governança corporativa sobre o nível de exportação. O sinal positivo do coeficiente corrobora a hipótese inicial e os estudos de Pereira e Sheng (2013) de que boas práticas de governança corporativa influenciam o percentual de exportações.

Como contribuições, esse trabalho apresentou uma análise separada dos indicadores de internacionalização (percentual de exportação e ADRs), o que permitiu mensurar comportamentos opostos dessas variáveis em relação à qualidade da governança.
No que tange às $\mathrm{ADRs}$, os resultados apontaram que sua comercialização tem relação negativa com a qualidade da governança corporativa, contrariando alguns estudos sobre o tema e questionando a utilização de ADRs como mecanismo para compensar uma possível ineficiência de gestão. Dessa forma, os resultados dessa pesquisa apontam que empresas brasileiras com níveis de governança mais elevados apresentam possibilidades de incrementar suas receitas pelas exportações, em contrapartida, empresas com baixos índices de governança tendem a buscar financiamentos no exterior como forma de mitigar os problemas de gestão.

Sugere-se como futuras pesquisas a inclusão de outros indicadores de internacionalização como percentual de ativos externos e percentual de funcionários estrangeiros e a utilização de outros modelos de regressão tais como o three-stage least-squares (3SLS).

\section{REFERÊNCIAS}

AMARAL, H. F. et al. Qualidade da governança corporativa das empresas na BOVESPA e internacionalização: Evolução 2002 - 2005. In: CONGRESSO DO INSTITUTO FRANCO-BRASILEIRO DE ADMINISTRAÇÃO DE EMPRESAS, 2007, Porto Alegre: IFBAE. Anais..., Porto Alegre, IFBAE, 2007.

\section{ANDRADE, A.; ROSSETTI, J. P. Governança}

corporativa. São Paulo: Atlas, 2004.

ANDRADE, L. P. et al. Governança Corporativa: uma análise da relação do conselho de administração com o valor de mercado e desempenho das empresas brasileiras.

Revista de Administração Mackenzie, São Paulo, v. 10, n. 4, p. 4-31, 2009.

ANDRADE, A. M. F; GALINA, S. V. R. Efeitos da internacionalização sobre o desempenho de multinacionais de economias em desenvolvimento.

Revista de Administração Contemporênea, São Paulo, v. 17, n. 2, p. 239-262, 2013.

BABIC, V. Corporate governance problems in transition economies. Winstom-Salem: Wake Forest University, Social Science Research Seminar, 2003. 
BARCELLOS, E. P. Internacionalização de Empresas Brasileiras: um estudo sobre a relação entre o grau de internacionalização e desempenho financeiro. Dissertação de Mestrado em Administração de Empresas da Faculdade de Economia, Administração e Contabilidade da Universidade de São Paulo, 2010.

BARRETO, A.; ROCHA, A. A expansão das fronteiras: brasileiros no exterior. In: ROCHA, A. (Org.).

As novas fronteiras: a multinacionalização das empresas brasileiras. 1. ed. Rio de Janeiro: Mauad, 2003.

BM\&FBOVESPA. Empresas Listadas. [2014].

Disponível em: <http://www.bmfbovespa.com.br/ cias-listadas/empresas-listadas/BuscaEmpresaListada. aspx? idioma $=$ pt-br $>$. Acesso em: 27 jul. 2014.

CARVALHAL-DA-SILVA, A. L.; LEAL, R. P. C. Corporate governance index, firm valuation and performance in Brazil. Revista Brasileira de Finanças, Rio de Janeiro, v. 3, n. 1, p. 1-18, 2005.

CLAESSENS, S. et al. Disentangling the incentive and entrenchment effects of large shareholdings. The Journal of Finance, USA, v. 57, n. 6, p. 2.741-2.771, 2002.

CLAESSENS, S.; LAEVEN, L. Financial Development, Property Rights, and Growht. The Journal of Finance, USA, v. 58, n. 6, p. 2.401-2.436, 2003.

\section{CORREIA, L. F. Um índice de governança para} empresas no Brasil. 2008, 274f. Tese (Doutorado em Administração) - Centro de Pós-Graduação e Pesquisa em Administração, Faculdade de Ciências Econômicas, Universidade Federal de Minas Gerais (CEPEAD-FACEUFMG), Belo Horizonte, 2008.

CORREIA, L. F; AMARAL, H. F; LOUVET, P. Um índice de avaliação da qualidade da governança corporativa no Brasil. Revista Contabilidade \& Finanças - USP, São Paulo, v. 22, n. 55, p. 45-63, 2011.

DUNNING, J. H. The geographical sources of the competitiveness of firm: some results of a new survey.

Transnational corporations, USA, v. 5, n. 3, p. 1-29, 1996.

FÁVERO, L. P. Análise de dados: modelagem multivariada para tomada de decisões. Rio de Janeiro: Elsevier, 2009.
FRIEDMAN, T. L. O Mundo é plano: uma breve história do século XXI. Rio de Janeiro: Objetiva, 2005.

HERMALIN, B. E.; WEISBACH, M. S. Board of directors as an endogenously determined institution: a survey of the economic literature. Federal Reserve Bank of New York Economic Policy Review, New York, 2003.

HIMMELBERG, C.; HUBBARD, G.; PALIA, D.

Understanding the determinants of managerial ownership and the link between ownership and performance.

Journal of Financial Economics, USA, v. 53, p. 353384, 1999.

IQUIAPAZA, R.; LAMONIER, W.; AMARAL, H.

Asymemtric information and dividends payout at the São Paulo stock Exchange. Advances in Scientific and Applied Accounting. USA, v.1, n. 1, p. 1.001-1.014, 2008

JOHANSSON, J. K.; YIP, G. S. Exploiting globalization potential: U.S. and Japanese strategies. Strategic Management Journal, USA, v. 15, n. 1, p. 579-601, 1994.

KLAPPER, L. F; LOVE, I. Corporate governance, investor protection and performance in emerging markets. World Bank Policy Research Working Paper, USA, n. 2.818, 2002.

LA PORTA, R. et al. Law and finance. Journal of Political Economy, USA, v. 106, n. 6, p. 1.113-1.155, 1998.

LA PORTA, R. et al. Investor protection and corporate valuation. The Journal of Finance, USA, v. 57, n. 3, p. 1.147-1.170, 2002.

LAMEIRA, V. J. As relações entre governança e risco nas companhias abertas brasileiras. Revista Brasileira de Gestão de Negócios, Rio de Janeiro, v. 14, n. 42, p. 7-25, 2012.

LEAL, R. P. C.; SAITO, R. Finanças corporativas no Brasil. RAE eletrônica, [on-line], v. 2, n. 2, p. 1-15, 2003.

LEUZ, C.; NANDA, D.; WYSOCKI, P. D. Earnings management and investor protection: an international comparison. Journal of Financial Economics, USA, v. 69, n. 3, p. 505-527, 2003. 
LOPES, A. B.; WALKER, M. Firm-level incentives and the informativeness of accounting reports: An experiment in Brazil. Working Paper. 2008. Disponível em: <http:// ssrn.com/abstract $=1095781>$. Acesso em: 21 nov. 2013.

MANSI, S. A.; REEB, D. M. Corporate diversification: what gets discounted? The Journal of Finance, USA, v. 57, n. 5, p. 2.167-2.183, 2002.

MORCK, R.; SHLEIFER, A.; VISHNY, R. W. Management ownership and market valuation: an empirical analysis.

Journal of Financial Economics, USA, v. 20, n.1-2, p. 293-315, 1988.

NAKAYASU, G. N. O impacto do anúncio da adesão das ações aos níveis diferenciados de governança corporativa no Brasil. São Paulo, 2006. $134 f$.

Dissertação de Mestrado do Programa de Pós-Graduação, Universidade de São Paulo, São Paulo, 2006.

\section{NICKELS, W. G.; WOOD, M. B. Marketing:}

relacionamentos, qualidade, valor. Rio de Janeiro: LTC, 1999.

OHMAE, K. Managing in a Borderless World. Harvard Business Review, USA, v. 67, n. 3, p. 152-161, 1995.

OCDE - Organização para Cooperação e

Desenvolvimento Econômico. Relatório Oficial sobre

Governança Corporativa na América Latina. [2004].

Disponível em: <http://www.oecd.org/corporate/ca/ corporategovernanceprinciples/24277169.pdf > . Acesso em: 18 nov. 2014.

OESTERLE, M. J.; RICHTA, H. N.; FISCH, J. H. The influence of ownership structure on internationalization. International Business Review, USA, v. 22, p. 187201, 2013.

\section{PEIXOTO, F. M. Governança corporativa,}

desempenho, valor e risco: estudo das mudanças em momentos de crise. 2008, 216f. Tese (Doutorado em Administração) - Centro de Pós-Graduação e Pesquisas em Administração, Faculdade de Ciências Econômicas, Universidade Federal de Minas Gerais (CEPEAD-FACEUFMG), Belo Horizonte, 2012.
PEROBELLI, F. F. C.; LOPES, B. S.; SILVEIRA, A. M. Planos de Opções de Compra de Ações e o valo das Companhias Brasileiras. Revista Brasileira de Finanças, Rio de Janeiro, v. 10, n. 1, p. 105-147, 2012.

PEREIRA, V. S. Ensaios sobre os efeitos da internacionalização na estrutura de capital $e$ estrutura de propriedade de multinacionais latino-americanas. 2013. 138f. Tese (Doutorado em Administração) - Escola de Administração de Empresas de São Paulo, Fundação Getúlio Vargas, São Paulo, 2013.

PEREIRA, V. S. SHENG, H. H. Os Efeitos da Internacionalização na Estrutura de Propriedade. In: XIII ENCONTRO BRASILEIRO DE FINANÇAS, 2013, Rio de Janeiro: SBFIN. Anais... Rio de Janeiro, 2013.

RAPPAPORT, A. Creating shareholder value: a guide for managers and investors. 2. ed. New York: The Free Press, 1998.

REVISTA EXAME. Maiores empresas do Brasil em 2013. [2013]. Disponível em: <http://exame.abril.com. $\mathrm{br} /$ negocios/melhores-e-maiores/> . Acesso em: 27 jul. 2014.

ROGERS, P. Governança corporativa, mercado de capitais e crescimento econômico no Brasil. 2006. 147f. Dissertação (Mestrado em Administração) Faculdade de Gestão e Negócios, Universidade Federal de Uberlândia, Uberlândia, 2006.

SILVEIRA, A. D. M. Governança corporativa: desempenho e valor da empresa no Brasil. Saint Paul Institute of Finance, USA, 2005.

SHLEIFER, A.; VISHNY, R. W. A. Survey of corporate governance. The Journal of Finance, USA, v. 52, n. 2, p, 737-783, 1997.

SULLIVAN, D. Measuring the degree of internationalization of a firm. Journal of International Business Studies, USA, v. 25, n. 2, p. 325-342, 1994.

UNCTAD - United Nations Conference on Trade and Development. World Investiment Report 2013:

Global Value Chains. Investment and Trade for Development, New York and Geneva, 2013. 